attached. The wound in conjunctiva was then closed with sutures. Relief to pain followed, and the condition of eye improved. On October 19th it is noted: "The eye has gradually cleared up and the vitreous has now become clear; the opacity of lens has not become greater and tension of eyeball is good. In the fundus, to the outer side of the disc, at a little distance from it, is a whitish spot of exudation nearly as large as the disc. This appears to be the foreign body, although no fragment is definitely visible. V. $=\frac{3}{\gamma}$."

(35). J. R., aged 31, was struck by a piece of steel, which had passed through the cornes and lens into the vitreous. The piece of steel was seen in the vitreous close to the retina. The vitreous was a little turbid, and it could not be positively affirmed whether the fragment was fixed in the retina or not. The 'case was explained to the patient, and it was decided to attempt removal with the electro-magnet. This was introduced, after separating the conjunctiva as in the preceding cases, through an incision between the inner and lower recti. It was passed up towards the position indicated, but without succese. In a day or two he was as well as before the operation.

(36). G. W., aged 27, admitted into infirmary October 4th, 1888 . Four days previously left eye injured by piece of steel from cutter for forks. On admission, suffering acute pain; severe iritis, hypopyon; penetrating wound in ciliary region, above and a little to inner side. Electro-magnet introduced witbout success. Enucleation on October 29th. Minute fragment found embedded in effusion at the back of vitreous.

Vitreous. (37).-N., whilst at his work on August 12th, 1885 , and using a hammer and chisel, was struck by a piece of steel in the left eye. He immediately came to the infirmary, when a wound was found in the upper and inner portion of the sclerotic. The vitreous was filled with blood and no foreign body was visible. The magnet was advanced to the wound, but no search was made. The bæmorrhage in the vitreous gradually cleared up, and the foreign body was observed coated over with yellowish white matter in the vitreous behind and below the lens. On October 6th the electro-magnet was introduced through an incision in the sclerotic, between the external and inferior recti. It was advanced up to the whitish mass and was felt to push it in front of it, but no sufficient attraction to move the fragment was detected. Enucleation was advised, and performed on October 26th. The fragment was found in the situation named surrounded with a dense mass, almost organised exudation, and the piece itself was thickly costed.

ADDENDUM.

Retina-Vitreous (38.)-J. W. C., aged 21, first seen June 21st, 1890 , six weeks after injury to left eye; fragment fixed in retins below disc, vision $\frac{2}{2} \frac{0}{0}$. Some months later the foreign body had shifted its position and could not be seen, vision gradually deteriorated, and in consequence of pain, iritis, etc., sclerotic was punctured (August 4th, 1890), and fragment extracted with point of electro-magnet. Now $\mathrm{V}=$ fingers, and is improving. Fragment weighed 0.188 grain.

Optic Nerve-Orbit (39).-J. W., aged 17, accident to left eye September 26th, 1890 . Splinter passed through edge of cornes and iris and lens. September 27th. Electro-magnet passed into vitreous, " clicked " fragment at back of eye but did not extract it. October 7th. Globe enucleated; scissors pressed splinter out of nerve at time of section, and it was removed loose from orbit with electro-magnet. Splinter weighed 1.01 grain.

Cornea (40).-J. C., splinter embedded in cornea three days. August $26 \mathrm{th}, 1890$. Tissue raised over it and removed with magnet. Weight 4 milligrammes.

Dr. Gustave Monod, some time Professor in the Faculté de Médecine, Paris, died on October 16th, at the age of 86 . He belonged to a highly respected family of Swiss origin, several memhers of which have been prominent pastors in the French Protestant Church. Dr. Monod leaves a son who is an agrégé of the Paris Medical Faculty and surgeon of the St. Antoine Hospital.

Factory Medical Service in Russia.-The Russian Government is about to issue an ord $3 r$ according to which: 1, every factory or mill situated at 8 versts (about $8 \frac{1}{2}$ kilomètres) or more from a town shall have a hospital of its own, containing from ten to seventy beds, according to the number of hands employed by the proprietor, as well as its own dispensary; 2, a special doctor and a medical assistant (Feldsher) must also be in attendance; 3 the district medical officer must exercise senitary control of all factories and mills existing in his district,

\section{THE TREATMENT OF PERFORATING ULCER} IN LEPROSY.

Presented to the Section of Surgery at the Annual Meeting of the British Medical Association at Birmingham, July, 1890.

BY BEAVEN RAKE, M.D.LOND.,

Medical Superintendent of the Trinidad Leper Asylum.

I HAVR spoken elsewhere ${ }^{1}$ of the treatment of perforating ulcer by stretching the external popliteal or great sciatic. This is followed by good results in many cases, especially when the ulcer is accompanied by pain in the course of the nerves.

During the past year I have tried in several cases another mode of treatment which is simpler, and is often efficacious. It consists in passing a bistoury through from the ulcer on the sole of the foot to the dorsum, and cutting . straight forwards through all tissues, bringing the bistoury out between the toes. The incision is then stuffed with lint to arrest bæmorrhage and prevent immediate closure of the wound, which is then left to granulate up from the bottom. If the ulcer should happen to be near the inner or outer side of the foot the knife can be brought out on either of these surfaces as the case may be. Subjoined are a few examples:-

CASE I.-I., Hindu, aged 49; has suffered from anæsthetic leprosy for thirteen years. January 3rd, 1890. Perforating ulcer of right foot. Bistoury passed through to dorsum and all tissues slit up forward to between toes. Wound stuffed. January 8th. A little swelling of dorsum. January 27th. Wound opened up again and some dead tissue scraped away. February 1st. Incision granulating up from bottom; still some pain in foot.

CAsR Ir.-K., Hindu, aged 40 ; suffering from anæsthetic leprosy for two years. May 8th, 1889. Left foot swollen. Sinus between fourth and fifth toes incised. Much granulation tissue scraped away. Bone too firm to come away. May 22nd. Foot still swollen. Loose head of metatarsal removed from between last two toes. Wound plugged with lint. May 24th. Abscess has burst on dorsum. Probe passed from this to sinus between toes and all tissues slit up. Wound stuffed with lint. February 1st, 1890. Incision firmly healed, with exception of small ulcer on third toe. No pain or swelling.

CASE IIr.-K, Hindu, aged 35; suffering from anæsthetic leprosy for five years. January 8 th, 1890. Luft great toe amputated. January 13th. Sinus opening on sole near stump; probe passed through to dorsum and all tissues slit forward. Incision stuffed with lint. February 1st. Incision nearly healed. Granulating surface where toe was amputated. No sinus or dead bone.

CASE IV.-B., Hindu, aged 42, suffering from anæsthetic leprosy for six years. August 21st, 1889. Two perforating ulcers on left sole, one between first and second toes, the other between third and fourth. Bistoury passed through to dorsum in each case, and tissues slit forward. Incision stuffed with lint. August 28th. Head of first metatarsal removed. August 30th. Left great toe amputated circularly. September 9 th. Fragment of bone removed. October 2nd. Fragments of second metatarsal removed. November 1st. More fragments removed. February 1st, 1890. Both incisions firmly healed; thick cicatrix. No pain.

CasE V.-S., Hindu, aged 44, suffering from anæsthetic leprngy for seven years. June 15th, 1889. Perforating ulcer of right foot. Probe passed through to dorsum and counter-opening made. July 29th. Bistoury passed throngh, and all tissues slit forwards to between toes. Incision stuffed with lint. August 5th. Granulating well; no pain. Another sinus slit up. August 16th. Necrosed head of bone loose; removed. Granulations look healthy. August 21st. Incision healing well from bottom. February 18t, 1890. Incision firmly healed; long thin cicatrix. Chronic ulcer atill on sole in old place; not perforating; no pain.

CAsE VI.-E. R., negro, aged 30. suffering from anæsthetic leprosy for five years. August 16th, 1889. Perforating ulcer of left foot. Bietoury passed through to dorsum and tissues slit forward. Fragments of bone removed; wound stuffed. September 13 tb. Incision granulating at bottom; sides cicatrising. December 6th. Perforating ulcer of right foot. Probe passed to dorsum, and all tissues slit forward with bistoury. Incision in left foot has healed well ; deep groove and firm cicatrix at bottom.

1 Report on the Trinidad Leper Asylum for 1887, and Lancet, September 17th 1887 , p. 593 . 
December 12th. Fragment of bone removed from stump of right great toe; small piece of dead bone removed from left dorsum. January 3rd, 1890. More fragments removed. February 1st. Left foot : incision healed up from bottom, leaving deep groove; some sinuses further back. Right foot : deep groove in site of incision; some ulceration at bottom of groove and on dorsum; some pain in foot.

CAss VIr.-C., Mussulman, aged 36, suffering from anæsthetic leprosy for six years. June 3rd, 1889. Ulcer has perforated through to dorsum of left foot. June 7 th. Probe passed from dorsum to sole, and all tissues slit forward through one toe. Wound plugged with lint. November 20 th. Sinus near little toe incised, and numerous loose fragments of bone removed. December 3rd. Commencing gangrene of foot. Sinus slit up and numerous fragments of dead bone removed. Wound stuffed. December 6th. Granulating well. February 1st, 1890. One incision firmly healed between last two toes. Other incision on outer side of foot is granulating up. Another sinus is forming further back.

CasR vIrr.-M., Hindu, aged 35, suffering from anæsthetic leprosy for five years. August $12 \mathrm{th}, 1889$. Perforating ulcer of left sole. Bistoury passed to dorsum and tissues slit up forward. Wound stuffed with lint. August 19th. Has lost middle toe from gangrene. August 21st. Granulating well. August 30th. Head of metatarsal and other fragments of bone removed. October 25th. Incision healed up, but perforating ulcer is still left: Bistoury passed through to dorsum again, and operation repeated. Fragments of skin cut away with scissors. February 1st, 1890. Incision nearly healed. Still some granulations at upper part, where toe was lost.

When we remember that perforating ulcer is a trophic lesion associated with distinct changes in the nerve trunks higher up, the measure of success attained in the above cases is somewhat surprising. It is true that in Case VIIr the perforating ulcer returned in two months, and had again to be dealt with; but up to the present time-three months after the second operation-it has not returned again. In Case $\nabla$ a chronic ulcer has appeared in the sole in the site of the old perforating ulcer, but it has not yet begun to perforate. In Case vr there is still ulceration on the dorsum of the foot, and in Case vIr another sinus is forming further back. It is possible that these may develop later into perforating ulcers. It is difficult to give a rationale for the success of the operation, but it seems to promise well, and is worth trying further. In cases where the perforating ulcer returns, it may be well to repeat the incision in conjunction with nerve stretching. The operation, though at first sight it may appear somewhat heroic, is only a modification of the well-known surgical practice of laying open a sinus, and stuffing it, so that it may granulate from the bottom.

\section{LEPROSY IN THE REPUBLIC OF COLUMBIA, SOUTH AMERICA. \\ BY EDWARD'H. HICKS, M.R.C.S.ENG., Bogota.}

THR local authorities have drawn attention to the alarming spread of leprosy lately in this republic. It is impossible to obtain reliable figures, but putting the entire population at 6,000 000 inhabitants, the lowest estimate gives 18,000 lepers. The tuberculated, non-tuberculated, and mutilating forms are all met with, the tubercular form being the most common.

In this country, the disease occurs chiefly in places having a temperature of $73^{\circ} \mathrm{F}$. or $64^{\circ} \mathrm{F}$, damp and low-lying districts being especially favourable for the development of the disease; whilst places having a temperature of $80^{\circ} \mathrm{F}$. and upwards seem to have some influence in mitigating the course of the disease. This is seen in the Government lazaretto at Agna-de-Dios, two and a half days' journey from here. Here the unfortunate victims undoubtedly obtain some relief from their sufferings, and in some cases improve sufficiently to be able to earn their own living, though no systematic course of treatment is adopted at that establishment. Very fow cases are reported from places having a temperature of $80^{\circ} \mathrm{F}$., and of those cases nearly all are said to have contracted the disease in colder climates.

In favour of the contagious nature of the disease there is the strongest evidence. In districts in which the disease was formerly unknown, it has appeared and spread with great rapidity, the first cases appearing shortly after the return of former inhabitants of the district who had contracted the disease in a distant province, but contagion seems only to have occurred where the leprous and the healthy lived together on terms of great intimacy, eating and drinking out of the same vessels and using the same clothes. On the other hand, where more attention was paid to cleanliness, cases are recorded where the healthy remained unaffected.

As regards the hereditary aspect, no case is recorded of children being born leprous, but the offispring of lepers have become lepers generally about puberty or a fow years later, though some show signs as young as 6 years of age; but considering the bad hygienic conditions generally present, many of these so-called hereditary cases may really be due to contagion.

As to articles of diet, the greater number of cases occur where fish cannot be obtained; in these places; hog's flesh in various forms, impure water, the immoderate use of cayenne pepper and chicha, a drink made from the fermentation of maize, are considered as favourable to the development of the disease.

The race most frequently attacked are the whites, next the mixed Indians and whites, then the pure Indian, and finally the (African) negro race, which seems to be the least frequently attacked.

The principal other diseases occurring in leprous districts are, in order of frequency, malarial fevers, various hepatic diseases, dysentery, rheumatism, and scrofula.

That localities of a certain temperature, namely, from $64^{\circ} \mathrm{F}$. to $73^{\circ} \mathrm{F}$., are the most infected districts there is no doubt ; and it is popularly believed that sudden changes of temperature from heat to cold are frequently the means of producing the disease.

Another factor I believe in producing the disease, speaking, of course, of Colombia, lies in the poor and insufficient food, bad ventilation, and overcrowding, so common among the poorer classes in this country.

\section{ABSTRACT OF AN ESSAY ON ALBUMINURIA IN THE APPARENTLY HEALTHY :}

Being the Prize Essay of the Border Countres Branch of the British Medical Association, 1890.

Bx JOHN MASON, M.D.CAM.B.,

Formerly House-Surgeon, House-Physician, and Resident Obstetric Physician at St. Bartholomew's Hospital.

Since the publication of Dr. Moxon's paper on Chronic Intermittent Albuminuria in 1878, the subject of albuminuria in persons who are apparently in perfect health has been largely discussed at meetings of the British Medical Association and in the journals; but the views expressed by leading men differ widely.

Six years since my attention was specially called to this subject by the accidental discovery of albumen in the urine of a patient who seemed to be not only healthy, but particularly robust and active, and who offered me every opportunity of prosecuting my inquiries.

Accidental Albumen, or Albumen which does not come from the Kidneys. - There is one cause for this, mentioned by Sir Andrew Clark, which I have made the subject of some observations. He says: "In some young men, excited by sexual desire and denying it indulgence, there is secreted from the urethra or its adjacent glands a fluid, which, mixing with the urine, yields evidence of the presence of serum albumen." The difficulty can be easily avoided by instructing the patient to clear the urethra first with a jet of urine, and submitting only what follows to examination; but I am convinced even this precaution is unnecessary, as the glairy fluid which is exuded from the urethra during eexual excitement does not give the reactions of serum albumen; for example: On Novem b $3 r$ 3rd, 1885, two specimens of urine were taken; the first contained a little mucus, no spermatozoa or cells, no albumen (picric acid and nitric acid cold). On November 24th the urine was specially examined on account of mucous secretion ; that passed first only was examined ; flocculent mucus throughout-otherwise clear; strongly acid, no albumen. On November 27th. Mucous secretion into urethra; urine 1022, no albumen. December 2nd. Great sexual feeling and secretion of mucus in night, 1034, acid, no albumen. I have notes of many other occasions to the same effect.

Not only is this mucus deroid of albumen, but seminal fluid, 